\title{
AORGANIZAÇÃO E A GESTÃO DA ESCOLA: UM OLHAR A PARTIR DOS ESTUDOS DE NORBERT ELIAS
}

FALSARELLA, Ana Maria. Doutora em Educação pela Pontifícia Universidade Católica de São Paulo PUC-SP. Professora pesquisadora do Centro Universitário de Araraquara - UNIARA. Líder do Grupo de Pesquisa Organização e Gestão de Instituições Educativas, certificado pela Uniara e registrado no CNPq. Endereço para correspondência: Rua Diogo Ortiz, 175, São Paulo-SP, CEP 05077-100. E-mail: anafalsarella@gmail.com; anamariafal@uol.com.br.

\section{Resumo}

O sociólogo Norbert Elias (1897-1990) é considerado um dos mais influentes intelectuais da contemporaneidade. Sua obra é uma das janelas conceituais que pretendemos abrir nos estudos de nosso Grupo de Pesquisa. Considerando que a tarefa básica da pesquisa nas ciências humanas é tornar os processos sociais mais acessíveis à compreensão dos sujeitos dentro das teias sociais em que transitam, este texto tem por objetivo explorar alguns conceitos inter-relacionados propostos por Elias em que ele assinala os padrões mutáveis de interdependência entre indivíduos e sociedade e a repercussão desses padrões dentro dos grupos sociais. Portanto, o procedimento utilizado foi o de revisão da literatura. Como resultado de nosso estudo, expomos alguns elementos-chaves do pensamento do autor, a saber, configuração, interdependência, jogo, poder e movimento. A título de conclusão entendemos que tais elementos, aplicados às questões educacionais, possibilitam ampliar o entendimento sobre a escola e outras instituições educativas. Assim, após explorar tais concepções, buscamos associá-las à área educacional, entendendo que elas podem constituir fonte teórica de grande valia para provocar reflexões e ampliar a compreensão sobre o funcionamento de instituições educativas, emespecial sobre a escola. E ainda porque, de uma perspectiva ampla das macrorrelações sociais, entendemos que estudar a escola é também estudar os problemas da sociedade. Os estudos de Elias nos abrem a possibilidade de olhar a escola não como se tirássemos uma fotografia e a analisássemos como uma instituição estática, paralisada em um instantâneo, mas como instituição social dinâmica, flexível, construída e desconstruída permanentemente pelo movimento de inter-relação entre as pessoas que dela fazem parte.

Palavras-Chave: Organização e gestão escolar; Configuração; Jogo; Norbert Elias.

\section{School organization and management: a look based on Norbert Elias' studies}

\begin{abstract}
The sociologist Norbert Elias (1897-1990) is considered one of the most influential intellectuals of contemporaneity. His work is one of the conceptual windows that we intend to open in the studies of our research group. Considering that the basic task of research in the humanities is to make the social processes more accessible to the understanding of individuals within the social webs in which they are inserted, this paper aims to explore some interrelated concepts proposed by Elias in which he notes the changing patterns of interdependence between individuals and society and the impact of these standards within social groups. Therefore, the methodological procedure was the literature review. As a result of our study we present some keyelements of the author's thought, namely, configuration, interdependence, game, power and movement. To conclude, we believe that such elements, applied to educational issues, allow to expand the understanding of school as well as other educational institutions. So, after exploring these concepts, we tried to link them to the field of education, understanding that they may be a source of great theoretical value to provoke reflection and broaden the understanding of the functioning of educational institutions, especially about school. And because, from a broad
\end{abstract}


perspective of social macro relations, we believe that to study school is also to study the problems of society. The studies of Elias allow us to look at school not as if we took a picture and analyzed it as a static institution, paralyzed in an instant, but as a social dynamic, flexible institution built and deconstructed permanently by the movement of the interrelationship between people who are part of it.

KEYWORDS: School organization and management; Configuration; Game; Norbert Elias.

\section{INTRODUÇÃO}

E é dessa maneira que a sociedade humana avança como um todo; é dessa maneira que toda a história da humanidade perfaz seu trajeto:

De planos emergindo, mas não planejada, Movida por propósitos, mas sem finalidade.

(ELIAS, 1994, p. 59)

Norbert Elias tece críticas a teorias sociológicas convencionais, principalmente ao funcionalismo e ao estruturalismo, cujos teóricos associam as estruturas sociais a padrões de coerção que exerceriam influência total sobre o comportamento dos indivíduos e, raramente, abordam a noção de indivíduo como pessoa singular que intervém nessas estruturas.

Grosso modo, podemos destacar o seguinte: o funcionalismo é uma corrente sociológica associada inicialmente a Émile Durkheim e posteriormente a Talcott Parsons e que influenciou o pensamento sociológico principalmente até os anos 60 do século passado. Explica os fatos sociais em termos de funções realizadas por instituições e suas consequências para a sociedade como um todo. A sociedade é comparada a um organismo vivo (como na biologia), em que cada diferente instituição exerce uma determinada função social específica que é essencial ao funcionamento do conjunto. Disso decorre que o mau funcionamento de uma instituição afeta toda a sociedade. Um fato social é visto como exterior ao sujeito na medida em que existe antes dele próprio, e como coercivo na medida em que a sociedade se impõe sem seu consentimento. Críticas ao funcionalismo se referem, então, à visão determinista das funções sociais e à descrição das instituições sociais considerando seus efeitos e desconsiderando as causas dos fenômenos. Já o estruturalismo se originou com Ferdinand de Saussure em seu livro "Curso de linguística geral" (1916). Embora contenha muitas variações teóricas, tornouse uma das abordagens mais utilizadas para analisar a língua, a cultura e a sociedade na segunda metade do século XX. De modo geral, essa escola de pensamento procura explorar as inter-relações, ou "estruturas", por meio das quais os significados são produzidos e reproduzidos dentro de uma cultura, configurando sistemas de significação. Igualmente o estruturalismo é criticado pelo enfoque centrado em forças estruturais determinísticas sobre os sujeitos e os grupos sociais.

Para Elias, tais concepções sociais são reificantes e totalizadoras, pois veem os seres humanos não como sujeitos, mas como "coisas" ou "objetos" em sua totalidade. Em outras palavras: os estudos tradicionais sobre os indivíduos, os grupos e as sociedades são inaceitáveis na medida em que se pautam em modelos teóricos que entendem as estruturas sociais como objetos independentes do modo de ser particular de cada indivíduo, ou seja, apresentam concepções claras sobre as "pessoas em sociedade", mas falham na abordagem das "pessoas como indivíduos".

Nesse sentido, os horizontes dos estudos sobre a sociedade e dos estudos sobre o indivíduo ficam empobrecidos em função não de uma demarcação real entre os universos da sociologia e da psicologia, mas devido a uma compartimentação artificial entre sistemas de crenças e valores que iluminam artificialmente ora o indivíduo ora a sociedade. Tal separação entre "concepções da pessoa" e "concepções das pessoas na sociedade" constitui um contrassenso, pois divide o conceito de humanidade e trata indivíduo e sociedade como objetos de estudo distintos, até mesmo antagônicos, quando na verdade constituem dois níveis de estudo diferentes, porém inseparáveis, quando se pensa o mundo humano vivido, a existência do homem concreto frente às contingências do cotidiano. Ou seja, 
para Elias, a vida não se deixa enclausurar em esquemas compartimentados.

Nos termos do autor, é uma visão estreita e distorcida reduzir a tarefa sociológica ao levantamento de características abstratas que são comuns a membros distintos de grupos sociais. Embora sirvam como apoios úteis ao estudo de processos sociais mais amplos e complexos, inquéritos estatísticos sobre comportamentos humanos comuns não podem definir o problema de uma investigação.

Essas considerações nos permitem evidenciar a descontinuidade do pensamento de Elias em relação às propostas da sociologia clássica. Vejamos algumas de suas concepções e em que elas podem nos auxiliar na análise da organização e da gestão de instituições educativas.

\section{ConfiguraÇão, INTERdePEndênCIA, JOgo, PODER, MOVIMENTO}

O mundo visto de uma perspectiva ordenada é passível de controle: sabemos como agir, como prosseguir, qual será o próximo passo. O mundo visto de uma perspectiva configuracional confunde, é ambivalente, causa estranheza, não tem direção fixa, não obedece a esquemas pré-planejados. $O$ conceito de configuração permite entender essa existência social não ordenada.

Percebe-se facilmente, diz Elias, que os pressupostos teóricos que entendem a existência de indivíduos ou atos individuais sem a sociedade são tão fictícios quanto outros que explicam a existência da sociedade sem os indivíduos. Como instrumento de análise da vida social, Elias propõe o conceito de configuração, cuja utilização contribui para eliminar a rigidez do pensamento e afrouxar a fronteira entre os estudos sobre o indivíduo e os estudos sobre a sociedade, possibilitando superar polarizações e chegar a valores e ideias sobre indivíduo e sociedade distintos das propostas clássicas. Em outros termos, a existência da pessoa como ser individual é indissociável de sua existência como ser social. Nas palavras do autor: "Isso se expressa no conceito fundamental da balança nóseu, o qual indica que a relação da identidade-eu com a identidade-nós do indivíduo não se estabelece de uma vez por todas, mas está sujeita a transformações muito específicas" (ELIAS, 1994, p.9).

Sujeitos individuais existem em configurações, cujo ponto central está vinculado à concepção de interpenetração, representada por teias de relações interdependentes tecidas entre os indivíduos (os quais participam de diversas configurações sociais) e entre essas próprias configurações. Em todo grupo, sociedade e contexto histórico cada configuração é singular, única e diferenciada, mas inter-relacionada às demais. Nesse sentido, o conceito de configuração pode ser aplicado tanto a grupos pequenos quanto a grandes grupos, tais como famílias, escolas, cidades, camadas sociais ou Estados, sendo que em grupos menores as cadeias ou elos de interdependências são mais facilmente perceptíveis e compreensíveis.

Uma configuração é uma "abrangência relacional" em que o comportamento de muitas pessoas se enreda de modo a formar estruturas entrelaçadas; não é, portanto, simplesmente um agregado de átomos individuais (o que conforma uma visão atômica de sociedade). Não basta a compreensão de aspectos do comportamento ou das ações das pessoas individualmente consideradas; pelo contrário, considera-se uma pluralidade de indivíduos interdependentes que, ao se relacionar uns com os outros, ao mesmo tempo em que modelam a sociedade, modelam a si próprios, ou seja, empreendimentos individuais não ocorrem em um vazio de combinações sociais. Para melhor compreensão, podemos ainda destacar que:

$\checkmark$ Configurações são irredutíveis, o que significa que nem se podem explicá-las em função de algum tipo de existência independente dos indivíduos, nem em função de que os indivíduos existem independentemente delas (ELIAS e SCOTSON, 2000); assim, a condição prévia para se entender a formação de uma configuração é a interdependência (que pode ser de aliados ou de adversários);

$\checkmark$ Configurações são sínteses, sempre provisórias, do movimento da vida social, daquilo que pulsa na sociedade; 
$\checkmark$ Configurações são mutáveis: o equilibrio flutuante e tenso é uma característica estrutural do fluxo das relações nós-eu em cada configuração.

Para explicar o modo como se entrelaçam os fins e as ações dos homens, Elias apresenta o conceitometáfora de jogo, referindo-se à combinação provisória e dinâmica das relações sociais, ao movimento da vida social. Ele acredita que, quando se utiliza a imagem dos participantes de um jogo como metáfora das pessoas que formam as sociedades, é mais fácil repensar as ideias estáticas que se associam à maior parte dos conceitos correntes usados na sociologia. Como afirma: "Uma configuração é o padrão mutável criado pelo conjunto dos jogadores (...) a totalidade das suas ações nas relações que sustentam uns com os outros (...) configuração esta que forma um entrançado flexível de tensões" (ELIAS, 1999, p. 142).

$\mathrm{O}$ jogo se configura como uma lei geral do funcionamento social e é realizado com intermediação de regras, mais ou menos elásticas, mais ou menos explícitas, porém não é definido por elas somente, mas pelo movimento mental e físico dos jogadores ao valerse delas. O que dá forma à configuração é o padrão mutável cunhado durante o jogo, que compreende o conjunto criado pelos jogadores por intermédio de suas mentes e de suas ações nas relações com os outros. Pode-se até pensar no jogo como se ele tivesse existência própria, mas não a tem. Por exemplo: quatro pessoas que se sentam à volta de uma mesa para jogar cartas formam uma configuração porque suas ações são interdependentes; o decurso tomado pelo jogo, embora autônomo de cada um dos jogadores individuais, é resultado das ações de um grupo de indivíduos interdependentes.

Outro exemplo se refere a um jogo de futebol. Cada time forma uma configuração e os jogadores de cada lado seguem as configurações os combinados de suas equipes. Todavia, só podemos compreender o fluxo constante dos jogadores de um dos lados em relação ao fluxo constante dos jogadores do outro lado. Desse modo, quando em campo, o grupo total de jogadores forma outra configuração. De qualquer forma, cada configuração formada não é abstrata; pelo contrário, é tão concreta quanto cada jogador individual. Remeter o conceito de configuração apenas para a sua realidade material - número de jogadores e regras existentes significa, portanto, uma distorção.

Nesse contexto, a visão de poder passa de um "conceito de substância" para um "conceito de relação". Ou seja, nas configurações, que são sempre fluidas, móveis e mutáveis, há um equilíbrio do poder, que é flutuante, instável e elástico, que se move de um lado para outro, para diante e para trás. Tal equilíbrio não diz respeito unicamente à grande arena das relações entre os Estados, onde atrai grande atenção devido à evidência de ações espetaculares, mas constitui um elemento integrante de todas as relações humanas, de toda e qualquer configuração.

O equilíbrio flutuante é apontado por Elias como característica do fluxo de cada configuração. Isso significa que as configurações possuem dois ou mais aspectos diferentes ou até opostos que convivem entre si ou, em outras palavras, a ambivalência, ou falta de precisão, faz parte do conceito de configuração.

A modernidade rejeita a ambivalência porque vive sob o espectro do mundo ordeiro e de uma ciência que crê poder controlar e dominar totalmente as coisas da natureza e da sociedade. Como é evidente, contrariamente à visão de mundo de uma perspectiva ordenada, organizada e passível de controle, o terreno em que se movem as configurações é fugidio, não obedece a determinismos. No interior de uma configuração não há controle absoluto das trocas e relações, tendo ela, inclusive, poder de autodestruição. Assim, quando Elias explora o conceito de jogo em função do movimento dos jogadores individuais, acena para a possibilidade de incorporar a incerteza e a imprevisibilidade nos estudos sociais.

Os conceitos de configuração e de jogo (interrelacionados à interdependência, poder e movimento) apresentados por Elias são modelos que podem auxiliar uma melhor compreensão do equilíbrio de poder, não como uma ocorrência extraordinária, mas como algo do cotidiano. Sejam as diferenças de poder fortemente endurecidas ou relativamente maleáveis, o equilíbrio, que pode tender mais para um lado ou mais para outro, 
está sempre presente onde quer que haja uma interdependência entre pessoas, uma configuração, pois o poder não é como um amuleto que um indivíduo possui e outro não; é uma característica estrutural das relações humanas.

Esses modelos são úteis porque permitem uma visão mais livre das formas usuais de análise social, o que possibilita demonstrar de modo simplificado o caráter relacional do poder, tornar mais acessíveis à reflexão certos problemas relativos à vida social e, por fim, superar o hábito de utilizar o conceito estático de relação, relembrando que todas as relações, tal como os jogos humanos, são processos móveis sempre em construção.

\section{ESCOLA E DEMAIS INSTITUIÇÕES EDUCATIVAS}

Neste texto, o foco maior foi colocado na escola, mas lembramos que as mesmas considerações valem para outras instituições voltadas à educação formal e não formal. Tomando por base os estudos de Elias, podemos afirmar que toda escola forma uma configuração peculiar e única, em que sujeitos individuais se relacionam por intermédio do jogo social. Os jogadores são alunos, professores, gestores, funcionários, pais e possíveis outros atores. Há regras explícitas, legais, geralmente advindas de instâncias superiores do sistema. Tais instâncias adquirem concretude em grupos de pessoas que também formam configurações que se relacionam com a configuraçãoescola. Há regras implícitas, mais fluidas e mutáveis; todas que se materializamno movimento dos jogadores. Cada segmento forma um time e cada jogador está ligado às regras de configuração de seu time. $\mathrm{O}$ fluxo do jogo só pode ser entendido pelo uso (e pela possível mudança) das regras no movimento dos jogadores que medem forças. E nesse movimento, o poder é dividido, por mais peso que tenha um dos jogadores (o diretor, por exemplo) ou uma das configurações (a dos professores, por exemplo).

Essa é a situação básica sempre que indivíduos entram ou se encontram em relação uns com os outros, no nosso caso a escola. Demonstrações de força entre as pessoas e os grupos, maiores ou menores, ocorrem permanentemente entre professores e alunos, entre gestores e professores ou funcionários, entre pais e professores. Também, entre as esferas da administração central e a escola. De acordo com as circunstâncias pessoais e sociais, cada configuraçãoescola pode apresentar maior equilíbrio de poder em determinado momento. Em outros momentos, o equilíbrio será mais instável ou tenderá mais fortemente para um dos lados.

Na medida em que somos mais dependentes e mais dirigidos, o poder dos outros sobre nós é maior, quer essa dependência se dê pela utilização alheia de força bruta ou de força legal, por necessidade pessoal financeira ou de status na carreira, ou mesmo por indiferença de nossa parte. No entanto, não é comum que os indivíduos que compartilham uma configuração social tenham consciência de que participam desse jogo.

Pensando em situações concretas, tudo o que acontece na escola é resolvido por esse jogo: Qual professor ficará com qual turma? Qual o turno mais adequado para as crianças pequenas (manhã ou tarde)? Por que determinado professor não consegue controlar os alunos e os outros conseguem? Por que a escola anda suja apesar de existirem muitos funcionários? Quem resolve e quem controla o que será ensinado aos alunos? O que é ensinado (ou não) dentro da sala de aula? Por que os professores aceitam ou não as sugestões do coordenador pedagógico?

Em todas essas situações corriqueiras está implícita a questão: quem pode mais? É o diretor que atribui as classes ou são os professores que as escolhem? $\mathrm{Na}$ determinação dos turnos vigorará o interesse dos pais, dos professores ou dos alunos? Os alunos têm mais poder junto a alguns professores e menos junto a outros? Por quê? Quando não mantêm a escola adequadamente limpa, os funcionários estão demonstrando que têm mais poder que o diretor? As instâncias superiores do sistema têm quanto de influência na efetivação do currículo escolar? Que tipo de fragilidade tem o coordenador cuja liderança não é aceita pelos professores?

As negociações em torno do poder são questões fundamentais para a escola resolver continuamente. A 
tarefa não consiste em mostrar de uma vez por todas quem manda mais, mas simplesmente em desbloquear o tema, tornando-o acessível a todos os indivíduos que participam da configuração, de modo que possam pensar conjuntamente o que é melhor para que a aprendizagem aconteça da melhor forma possível.

Não só internamente o poder é disputado. A configuração-escola e as configurações dentro da escola (lembrando que cada classe, com seus alunos e professores, também formam configurações) são padrões mutáveis criados pelo conjunto de atores no jogo de relações internas e externas (com outras configurações, tais como secretarias de educação, coordenadorias de ensino e outras escolas).

\section{A título de conclusão}

Conforme já destacava Antônio Cândido em 1966:

A estrutura administrativa de uma escola exprime sua organização no plano consciente, e corresponde a uma ordenação racional, deliberada pelo Poder Público. A estrutura total de uma escola é todavia algo mais amplo, compreendendo não apenas as relações ordenadas conscientemente mas, ainda, todas as que derivam da sua existência enquanto grupo social. Isto vale dizer que, ao lado das relações oficialmente previstas, há outras que escapam à sua previsão, pois nascem da própria dinâmica do grupo social escolar. Deste modo, se há uma organização administrativa igual para todas as escolas de determinado tipo, pode-se dizer que cada uma delas é diferente da outra, por apresentar características devidas à sua sociabilidade própria (ANTONIO CÂNDIDO, 1966, p.107).

Nos estudos sobre educação, afirma Hutmacher (1999), o interesse tende a focalizar-se ou no centro político-administrativo ou na sala de aula. Mas entre essas duas perspectivas existe o espaço da instituição, que, no caso da escola, articula a sala de aula às demais instâncias do sistema, exercendo um papel intermédio.
Então, um campo determinante da pesquisa educacional está no pensar sobre o lugar ocupado pela escola no sistema de ensino e na sociedade, não de forma generalizada, mas analisando cada instituição em suas particularidades. Ainda segundo esse autor, apesar de a organização, o emprego do tempo e das energias, bem como as regras do jogo das relações escolares, serem questões fulcrais, elas têm sido objeto de atenção mais reduzida por parte dos estudiosos.

Atentos a tais considerações, expusemos neste texto alguns elementos-chave do pensamento de Norbert Elias, a saber: configuração, interdependência, jogo, poder e movimento. Essas concepções constituem fonte teórica relevante, a nosso entender, para compor os estudos sobre a organização de instituições educativas, mormente no que tange à teia de relações e ao jogo de poder que vão conformando sua identidade e sua cultura peculiar.

Ao referir-se à estrutura reticular das configurações humanas, o autor faz uma analogia com a rede de tecido, em que a trama só é compreensível em termos da maneira como os fios se ligam em recíproca relação (ELIAS, 1994). Ao tomarmos as instituições educativas como objeto de estudo, depreendemos das ideias apresentadas por Elias que, em cada configuração formada, cada indivíduo é "um fio" na rede de interdependências condicionada pelas circunstâncias do mutável jogo relacional, jogo que se estabelece a partir da mobilização de regras implícitas e explícitas. Ao pertencer a um grupo social, cada indivíduo é o que é em relação aos outros, ao enovelar suas características individuais com a história das relações na escola, no sistema escolar e, em última instância, em toda a rede humana da qual é parte.

Dessa forma, de uma perspectiva ampla das macrorrelações sociais, estudar a instituição educativa é também estudar a sociedade e a forma como conduz a formação das mentalidades dos indivíduos. Por isso, é importante ao pesquisador olhar a instituição em movimento, em sua dinâmica sempre flexível, construída e desconstruída permanentemente pelo movimento interno e externo de inter-relações. Como destaca o próprio autor: 
E esse fato, o de cada "eu" estar irrevogavelmente inserido num "nós", finalmente deixa claro por que a entremeação dos atos, planos e propósitos de muitos "eus" origina, constantemente, algo que não foi planejado, pretendido ou criado por nenhum indivíduo (ELIAS, 1994, p. 57).

Sintetizando: as configurações educativas têm padrões mutáveis criados pelo conjunto dos indivíduos (alunos, professores, diretores, pais, supervisores, funcionários, secretários de educação, ministros), não só por seus corpos e intelectos, mas, sobretudo, pelo jogo de relações que sustentam uns com os outros. $\mathrm{O}$ pesquisador da área da educação tem, assim, nos estudos de Norbert Elias, valiosos instrumentos teórico-analíticos para estudar essas relações.

\section{REFERÊNCIAS}

CÂNDIDO, Antonio. Aestrutura da escola. In: PEREIRA, Luiz; FORACCHI, Marialice.

Educação e Sociedade. São Paulo: Nacional, 1966.

ELIAS, Norbert. A sociedade dos indivíduos. Rio de Janeiro: Zahar, 1994.

O conceito de configuração. In:
Introdução à Sociologia. Lisboa: Edições 70, 1999, p. 140-145.

ELIAS, Norbert; SCOTSON, John L. Os estabelecidos e os outsiders: sociologia das relações de poder a partir de uma pequena comunidade. Rio de Janeiro: Zahar, 2000.

HUTMACHER, Walo. A escola em todos os seus estados: das políticas de sistema às estratégias de estabelecimento. In: NÓVOA, António. As organizações escolares em análise. Lisboa: Dom Quixote, 1999, p. 43-76.

\section{Sugestões de leitura}

GONSALVES, Elisa P. O Conceito de configuração social em Norbert Elias - Espaço Social de ambivalência? DHP/Centro de Educação/UFPB, s/ d. Disponível emhttp://www.uel.br/grupo-estudo/ processoscivilizadores/.portugues/sitesanais/anais7/ Trabalhos/xO\%20Conceito $\% 20 \mathrm{de} \%$ 20Configuracao $\% 20$ Social $\% 20 \mathrm{em} \% 20$ Norbert $\%$ 20Elias.pdf. Acesso em 14.jun.2013.

HUNGER, Dagmar; ROSSI, Fernanda; SOUZA NETO, Samuel. A teoria de Norbert Elias: uma análise do ser professor. Educação e Pesquisa, São Paulo, v. 37, n. 4, dez.2011. 